\title{
Dysregulation of l-arginine metabolism and bioavailability associated to free plasma heme
}

F. Omodeo-Salè, L. Cortelezzi, Z. Vommaro, D. Scaccabarozzi and A. M. Dondorp Am J Physiol Cell Physiol 299:C148-C154, 2010. First published 31 March 2010; doi:10.1152/ajpcell.00405.2009

You might find this additional info useful...

This article cites 42 articles, 14 of which can be accessed free at:

http://ajpcell.physiology.org/content/299/1/C148.full.html\#ref-list-1

This article has been cited by 1 other HighWire hosted articles

Vascular risk assessment in patients with sickle cell disease

Claudia R. Morris

haematol, December 30, 2010; 96 (1): 1-5.

[Full Text] [PDF]

Updated information and services including high resolution figures, can be found at:

http://ajpcell.physiology.org/content/299/1/C148.full.html

Additional material and information about AJP - Cell Physiology can be found at:

http://www.the-aps.org/publications/ajpcell

This infomation is current as of September 2, 2011. 


\title{
Dysregulation of L-arginine metabolism and bioavailability associated to free plasma heme
}

\author{
F. Omodeo-Salè, ${ }^{1}$ L. Cortelezzi, ${ }^{1}$ Z. Vommaro, ${ }^{1}$ D. Scaccabarozzi, ${ }^{1}$ and A. M. Dondorp ${ }^{2,3}$ \\ ${ }^{1}$ Dipartimento di Scienze Molecolari Applicate ai Biosistemi (DISMAB), Università di Milano, Milan, Italy; ${ }^{2}$ Faculty of \\ Tropical Medicine, Mahidol University, Bangkok, Thailand; and ${ }^{3}$ Centre for Tropical Medicine, Churchill Hospital, Oxford, \\ United Kingdom
}

Submitted 8 September 2009; accepted in final form 28 March 2010

\begin{abstract}
Omodeo-Salè F, Cortelezzi L, Vommaro Z, Scaccabarozzi D, Dondorp AM. Dysregulation of L-arginine metabolism and bioavailability associated to free plasma heme. Am J Physiol Cell Physiol 299: C148-C154, 2010. First published March 31, 2010; doi:10.1152/ajpcell.00405.2009.Severe Plasmodium falciparum malaria is associated with hypoargininemia, which contributes to impaired systemic and pulmonary nitric oxide (NO) production and endothelial dysfunction. Since intravascular hemolysis is an intrinsic feature of severe malaria, we investigated whether and by which mechanisms free heme [Fe(III)-protoporphyrin IX (FP)] might contribute to the dysregulation of L-arginine (L-Arg) metabolism and bioavailability. Carrier systems "y+" [or cationic amino acid transporter (CAT)] and "y+L" transport L-Arg into red blood cells (RBC), where it is hydrolyzed to ornithine and urea by arginase (isoform I) or converted to $\mathrm{NO}$ and citrulline by endothelial nitric oxide synthase (eNOS). Our results show a significant and dose-dependent impairment of L-Arg transport into RBC pretreated with FP, with a strong inhibition of the system carrier $y+L$. Despite the impaired L-Arg influx, higher amounts of L-Arg-derived urea are produced by RBC preexposed to FP caused by activation of $\mathrm{RBC}$ arginase I. This activation appeared not to be mediated by oxidative modifications of the enzyme. We conclude that L-Arg transport across RBC membrane is impaired and arginase-mediated L-Arg consumption enhanced by free heme. This could contribute to reduced NO production in severe malaria.
\end{abstract}

malaria; ferriprotoporphyrin IX; arginase

IN DISEASES with prominent intravascular hemolysis such as malaria, thalassemia, and sickle-cell disease (SCD), the capacity of the scavenging proteins haptoglobin and hemopexin quickly becomes saturated and the subsequent increase in free plasma ferric heme exerts toxic, proinflammatory, and prooxidant effects adversely affecting endothelial function (37). Heme also promotes the expression of adhesion molecules (ICAM-1, VCAM, and E-selectin) on endothelium in vitro (37). This could increase endothelial adhesion of parasitized red blood cells (pRBC), which is a central feature of Plasmodium falciparum malaria pathophysiology characterized by sequestration and microvascular obstruction, with impaired perfusion (9).

In addition, we (26) and others (6) have previously shown that free heme can readily enter the RBC membrane, affecting its structural and rheological properties including a decrease in $\mathrm{RBC}$ deformability. The effects on the RBC are mediated by a heme-induced reduction in cell volume, oxidative injury, and/or phosphorylation of band 3 (24-26) and may contribute

Address for reprint requests and other correspondence: F. Omodeo-Salè, Dipartimento di Scienze Molecolari Applicate ai Biosistemi (DISMAB), Facoltà di Farmacia, Via Trentacoste 2, 20134 Milan, Italy (e-mail: fausta.omodeosale@unimi.it). to microvascular flow impairment in areas of intense sequestration where the lumen of the vessels is significantly reduced. In addition, studies performed in African children with cerebral malaria have demonstrated impaired production of nitric oxide (NO), whose deficiency might be also exacerbated by intravascular hemolysis increasing cell free $\mathrm{Hb}$, causing $\mathrm{NO}^{\circ}$ deactivation $(1,21)$. Beneficial effects of NO include the maintenance of normal platelet function through the downregulation of aggregation and adhesion $(31,32)$ and a decrease in cytokine production (10) and in cytoadherence of $\mathrm{pRBC}$ to the microvascular endothelium (35). RBC possess nitric oxide synthase (NOS) activity, and RBC NO is involved in the regulation of $\mathrm{RBC}$ deformability as well as in inhibition of platelet aggregation $(14,15,27,30)$. RBC NOS shares the common substrate L-arginine ( $\mathrm{L}-\mathrm{Arg}$ ) with arginase I, present in high concentration in erythrocytes and responsible for the hydrolysis of L-Arg to urea and L-ornithine. Low levels of plasma L-Arg are common in adults and children with severe cerebral malaria, are directly correlated with disease severity, and contribute to impaired NO production and endothelial dysfunction $(18,42)$. Different explanations for hypoargininemia in malaria have been suggested, such as cytokine-induced activation of arginase I and II (23), increase in plasma arginase (33), inadequate arginine adsorption by enterocytes, or endogenous biosynthesis or recycling (18).

The aim of the present study was to investigate the role of free heme in the dysregulation of arginine metabolism observed in malaria and other hemolytic diseases. We show that free heme compromises L-Arg transport into the RBC mainly through inhibition of the carrier system " $y+L$ " and promotes intracellular L-Arg degradation by activation of arginase I.

\section{MATERIALS AND METHODS}

Chemicals, blood, and reagents. Donor blood was kindly provided by the Association of Voluntary Italian Blood donors (AVIS), the national Italian nonprofit organization for blood donation. The ethical committee of AVIS authorized the use of blood for this research project with the informed consent of donors.

$\mathrm{L}-\left[2,3,4-{ }^{3} \mathrm{H}\right] \operatorname{Arg}(37 \mathrm{MBq} / 1 \mathrm{mCi})$ was from GE Healthcare Life Sciences. Other biochemicals were purchased from Sigma (Sigma Italia, Milan, Italy). Ferriprotoporphyrin IX (FP) and hematoporphyrin IX (HP) stock solutions were prepared daily by resuspension in DMSO and dilution in PBS, and porphyrin equivalents were quantified by reading the absorbance at $385 \mathrm{~nm}$ or $396 \mathrm{~nm}$, respectively $\left(\varepsilon_{385}\right.$ hematin $\left.=6.1 \times 10^{4} \mathrm{M} / \mathrm{cm}, \varepsilon_{396} \mathrm{HP}=2.72 \times 10^{-4} \mathrm{M} / \mathrm{cm}\right)$. Microvascular endothelial cells (HMEC-1) were kindly provided by Prof. Donatella Taramelli (Dipartimento di Sanità Pubblica-Microbiologia-Virologia, University of Milano). Cells were maintained in MCDB 131 medium (Invitrogen, Milan, Italy) supplemented with $10 \%$ fetal calf serum (HyClone), $10 \mathrm{ng} / \mathrm{ml}$ epidermal growth factor 
(Chemicon), $1 \mu \mathrm{g} / \mathrm{ml}$ hydrocortisone, $2 \mathrm{mM}$ glutamine, $100 \mathrm{U} / \mathrm{ml}$ penicillin, $100 \mu \mathrm{g} / \mathrm{ml}$ of streptomycin, and $20 \mathrm{mM}$ HEPES buffer, $\mathrm{pH}$ 7.4 (EuroClone).

Preparation of $R B C$, cell-free extracts, and $R B C$ membranes. Citrate/phosphate/dextrose (CPD)-anticoagulated blood was obtained from healthy A-positive donors and used within 5 days of withdrawal. Aliquots of blood were centrifuged at $1,850 \mathrm{~g}$ and $4^{\circ} \mathrm{C}$ for $5 \mathrm{~min}$, the buffy coat was removed, and the erythrocyte pellet was washed three times with 10 volumes of cold $\left(4^{\circ} \mathrm{C}\right)$ PBS. RBC were gently resuspended at $10 \%$ hematocrit (Hct) with PBS-5 mM glucose (PBSG) and used immediately after isolation. RBCs were exposed to FP for $60 \mathrm{~min}$ at $37^{\circ} \mathrm{C}$ under continuous gentle shaking. Cells were then pelleted by centrifugation at $1,850 \mathrm{~g}$ for $10 \mathrm{~min}$, washed twice with PBSG, and resuspended at $40 \%$ Hct in the same buffer but containing $5 \mathrm{mM}$ L-Arg. Suspensions of control or treated RBC were incubated at $37^{\circ} \mathrm{C}$ for the indicated times, and arginase activity was assessed in either the total suspension or the supernatant obtained by centrifugation $(1,850$ $g, 5 \mathrm{~min}$ ), in which the release of urea was also measured. Cell-free extracts (total lysates) were obtained by hypotonic shock of RBC in 5 $\mathrm{mM} \mathrm{NaHPO}_{4}$ buffer $\mathrm{pH} 8.0$ (5P8 buffer) and three freeze-thawing cycles. In some experiments, RBC cytosol and membranes were prepared by centrifugation for $30 \mathrm{~min}$ at $20,000 \mathrm{~g}$ of total lysates of control and FP-exposed RBCs. Membranes were extensively washed in 20 volumes of 5P8 buffer containing $0.1 \mathrm{mM}$ EDTA. A final wash of the membranes was performed in the same buffer without EDTA. RBC membranes $(300-400 \mu \mathrm{g}$ protein/250 $\mu \mathrm{l})$ or cytosol $(25 \mathrm{mg}$ $\mathrm{Hb} / 250 \mu \mathrm{l})$ was incubated with $5 \mathrm{mM} \mathrm{L}$-Arg and used for the determination of urea production.

Measurement of urea production and arginase activity. For urea determination, an aliquot of sample (cell-free extract, cytosol, or membranes) was diluted with half the volume of ice-cold $10 \%$ perchloric acid. The mixture was centrifuged, and an aliquot of the clear supernatant was added to $800 \mu \mathrm{l}$ of the acid mixture $\mathrm{H}_{2} \mathrm{SO}_{4}$ $\mathrm{H}_{3} \mathrm{PO}_{4}-\mathrm{H}_{2} \mathrm{O}(1: 3: 7, \mathrm{vol} / \mathrm{vol} / \mathrm{vol})$. Urea was colorimetrically measured at $540 \mathrm{~nm}$ after the addition of $50 \mu \mathrm{l}$ of $9 \% \alpha$-isonitrosopropiophenone (dissolved in $100 \%$ ethanol) and heating at $100^{\circ} \mathrm{C}$ for $45 \mathrm{~min}(8)$ and is reported per unit of $\mathrm{Hb}$ content.

For arginase determination an aliquot of the whole RBC suspension was lysed in 20-40 volumes of distilled water and activated for 45 min at $50^{\circ} \mathrm{C}$ in $75 \mathrm{mM}$ glycine- $0.75 \mathrm{mM} \mathrm{MnCl}_{2} \mathrm{pH} 9.5$ (1:1, vol/vol) (16). Arginase activity was measured as the quantity of urea formed after initiation of the reaction by the addition of $0.25 \mathrm{M}$ (final concentration) L-Arg ( $\mathrm{pH}$ 9.7), followed by a 30-min incubation at $37^{\circ} \mathrm{C}$ after which the reaction was stopped by adding the acid mixture. Arginase activity was also measured in RBC lysates incubated with FP or HP just before the addition of L-Arg and corrected for background values in a blank solution containing the same amount of FP or HP. Specific activity of arginase measured in the total RBC suspension, RBC supernatant, or RBC lysate was expressed as micromoles of urea produced per minute (U) per gram of $\mathrm{Hb}$. The activity of the membrane-bound arginase was expressed as $U$ per milligram of protein.

$K_{\mathrm{m}}$ of arginase of control and FP-treated RBC was determined by performing the enzyme assay in the presence of increasing concentrations of L-Arg (2-30 mM) and graphically evaluated with the Eadie-Hofstee graph.

Effect of oxidative stress on arginase activity. The effect of molecular oxygen and oxidative stress on arginase activity was investigated by different approaches. RBC were pretreated with the prooxidant system $0.3 \mathrm{mM} \mathrm{FeSO}_{4}-0.5 \mathrm{mM}$ ascorbate $\left(3 \mathrm{~h}, 37^{\circ} \mathrm{C}\right)$, with $40 \mu \mathrm{M}$ of the porphyrin isoform devoid of iron (HP) $\left(1 \mathrm{~h}, 37^{\circ} \mathrm{C}\right)$, or with the radical scavengers $5 \mathrm{mM} N$-acetyl-L-cysteine (NAC) or $100 \mu \mathrm{M}$ sulfosalazine (SZ) $\left(30 \mathrm{~min}, 37^{\circ} \mathrm{C}\right)$ before exposure to FP. Alternatively, before exposure to FP, Hb was "poisoned" and oxygen depleted by bubbling carbon monoxide $(\mathrm{CO})$ for $10 \mathrm{~min}$ into the RBC suspension. In this experiment the formation of $\mathrm{Hb}-\mathrm{CO}$ was verified by the analysis of the ultraviolet- visible (UV/Vis) spectra confirming the shift of the maximum absorbance of the RBC suspension from $414 \mathrm{~nm}$ to $420 \mathrm{~nm}$ (22).

Measurement of L-Arg influx into erythrocytes and HMEC-1 cells. Aliquots of control and FP-treated RBC (10\% Hct) were supplemented with $0.2 \mathrm{mM} \mathrm{L}-\left[{ }^{3} \mathrm{H}\right] \mathrm{Arg}$ and incubated at $37^{\circ} \mathrm{C}$ for $5 \mathrm{~min}$ for measurement of the initial flux rate. After incubation RBC were centrifuged $(1,000 \mathrm{~g}, 3 \mathrm{~min})$ and washed in cold PBSG. Packed cells were lysed with 2 volumes of $10 \%$ Triton X-100, and proteins were precipitated with 3 volumes of $10 \%$ ( $\mathrm{vol} / \mathrm{vol})$ trichloroacetic acid, followed by $\beta$-scintillation counting. The two saturable transport systems were investigated separately by performing the incubation in the presence of $2 \mathrm{mM} N$-ethylmaleimide (NEM) to inhibit the carrier system $\mathrm{y}+$ or in the presence of $1 \mathrm{mM}$ leucine to inhibit the carrier system $\mathrm{y}+\mathrm{L}(3)$.

HMEC-1 were seeded in quadruplicate at $1.5 \times 10^{5} /$ well in MCDB 131 medium in 24-well flat-bottom tissue culture clusters (Costar, 3596) and pretreated for $60 \mathrm{~min}$ with FP $(10-40 \mu \mathrm{M})$. At the end, cells were washed twice in PBSG and incubated for 5 min with 0.2 $\mathrm{mM} \mathrm{L}-\left[{ }^{3} \mathrm{H}\right]$ Arg in MCDB 131 medium. Cells were then washed twice in PBS and resuspended in $1 \mathrm{~N} \mathrm{NaOH}$ before $\beta$-scintillation counting.

$\mathrm{MetHb}$ determination. The concentration of MetHb was estimated from visible spectra of RBC hemolysate with the algorithm of Winterbourn (38), based on the measurement of optical densities at 560, 577 , and $630 \mathrm{~nm}$.

Statistical analysis. Results are reported as means with SD of at least four experiments run in three to five replicates, unless otherwise specified. Deviations from normal distribution were checked with the Shapiro-Wilk and Shapiro-Francia tests for normality. Comparisons between control and treated samples were made with a paired Student's $t$-test. For data that were not normally distributed and for comparisons in which the SD between the groups was not approximately equal, the Wilcoxon matched-pairs signed-ranks test was used. A test for trend across ordered groups was used to show dose response of arginine uptake to FP.

\section{RESULTS}

Activity of arginase in RBC pretreated with FP. The concentration of FP chosen for the experiments was kept below 40 $\mu \mathrm{M}$ to avoid hemolytic destruction of RBC above 2-3\%. RBC pretreated for $60 \mathrm{~min}$ with $40 \mu \mathrm{M}$ FP showed a mean increase in arginase activity of $\sim 20 \%$ (Table 1 ). Results reported in Table 1 refer to the arginase activities measured after 16-h incubation in relation to the $\mathrm{Hb}$ concentration measured at the end of the incubation. Although the reported results are after 16-h incubation, measurements just after the start of the incubation, and as a function of the length of incubation up to $16 \mathrm{~h}$, showed that the FP-mediated increase in arginase activity was immediate and that the extent of activation was independent from the incubation time (data not shown). As shown in Table 1, the measured FP-mediated arginase activation was the same in the complete RBC suspension compared with the extracellular medium. The radical scavengers NAC and SZ did not prevent the increase of arginase activity induced by FP. However, pretreatment of $\mathrm{RBC}$ with the prooxidant system $\mathrm{FeSO}_{4}$ ascorbate caused a mean increase of arginase activity of $10 \%$. $\mathrm{HP}$, the porphyrin analog devoid of iron, enhanced the arginase activity to the same extent as FP, strongly suggesting that heme-iron-mediated oxidative reactions are not involved.

As shown by the broad UV/Vis spectrum, FP is largely present in aqueous solutions as dimers and aggregates due to the formation of $\mu$-oxo linkages among iron atoms of the ferri heme units (4). L-Arg, at the same concentrations and $\mathrm{pH}$ used in the arginase assay, was found to change the UV/Vis spectrum of FP, causing 
Table 1. Total and extracellular arginase activity of human red blood cells in presence of heme products or pro- and antioxidant systems

\begin{tabular}{|c|c|c|c|c|c|c|}
\hline Fraction & Treatment & $n$ & $\begin{array}{l}\text { Arginase Activity (U/g Hb) } \\
\text { in Controls }\end{array}$ & $\begin{array}{c}\text { Arginase Activity }(\mathrm{U} / \mathrm{g} \mathrm{Hb}) \\
\text { After Treatment }\end{array}$ & Difference [mean $(95 \% \mathrm{CI})]$ & $P$ Value \\
\hline \multirow[t]{4}{*}{ Total } & FP $(40 \mu \mathrm{M})$ & 12 & $57.6 \pm 15.0$ & $69.5 \pm 15.8$ & $11.8(8.0-15.7)$ & $<0.001$ \\
\hline & FP $(40 \mu \mathrm{M})$ with NAC $(5 \mathrm{mM})$ & 5 & $56.8 \pm 8.3$ & $72.0 \pm 10$ & $15.2(9.0-21.5)$ & 0.003 \\
\hline & $\mathrm{Fe}(0.3 \mathrm{mM})$-ascorbate $(05 \mathrm{mM})$ & & & $63.3 \pm 3.4$ & $6.5(0.1-12.9)$ & 0.048 \\
\hline & $\mathrm{HP}(40 \mu \mathrm{M})$ & 8 & $55.5 \pm 2.3$ & $71.4 \pm 1.7$ & $15.9(13.3-18.5)$ & $<0.001$ \\
\hline Supernatant & FP $(40 \mu \mathrm{M})$ & 6 & $55.0 \pm 12.0$ & $72.2 \pm 15.0$ & $17.3(4.6-30.1)$ & 0.018 \\
\hline
\end{tabular}

Arginine activity values [in $\mu \mathrm{m}$ urea produced/min $(\mathrm{U}) / \mathrm{g} \mathrm{Hb}$ ] are means $\pm \mathrm{SD}$ for $n$ samples. Human red blood cells $(\mathrm{RBC})[0 \%$ hematocrit $(\mathrm{Hct})]$ were pretreated with Fe(III)-protoporphyrin IX (FP) or hematoporphyrin IX (HP) for $1 \mathrm{~h}$ at $37^{\circ} \mathrm{C}$ or Fe-ascorbate for $3 \mathrm{~h}$ at $37^{\circ} \mathrm{C}$. After this, $\mathrm{RBC}$ were washed twice in PBS-glucose and resuspended at $40 \%$ Hct in the same buffer. Arginase activity was assayed in the total suspension or the extracellular medium after $16-\mathrm{h}$ incubation. In a subset, $\mathrm{RBC}$ suspensions were exposed for $30 \mathrm{~min}$ at $37^{\circ} \mathrm{C}$ to $5 \mathrm{mM} \mathrm{N}$-acetyl-L-cysteine (NAC) or $100 \mu \mathrm{M}$ sulfosalazine (SZ) before treatment with FP. Arginase activity was compared in treated samples vs. controls by paired Student's $t$-test. CI, confidence interval.

a shift of the absorbance at $400 \mathrm{~nm}$ (Fig. 1A). This indicates the ability of L-Arg to interact with the FP $\mu$-oxo dimers and aggregates, possibly through inducing the formation of FP monomers and/or adducts of L-Arg-FP. In agreement with the recent paper by Coghi et al. (7), in which it is shown that heme solubilized by an excess of L-Arg maintains the capability of inducing iron-mediated oxidative reactions, we hypothesize that L-Arg and FP do not associate via the heme iron but through the interaction between the carboxylate and guanidine groups. We speculate also that the interaction of L-Arg with HP is identical to that with FP. However, $\mathrm{HP}$ in solution is predominantly nonaggregated (monomers), as shown by the sharp UV/Vis spectrum centered around $400 \mathrm{~nm}$, and the L-Arg-induced shift of the UV/Vis spectrum of HP is less prominent (Fig. 1B).

The interaction of L-Arg with FP was also demonstrated at $\mathrm{pH} 7.4$ (not shown), appeared to be specific for L-Arg (Fig. $1 C$ ), and could explain the increase of the apparent $K_{\mathrm{m}}$ value of arginase in FP-treated $\mathrm{RBC}(5.37 \pm 0.9 \mathrm{mM}$ vs. $3.96 \pm 0.8$ $\mathrm{mM}$ in control RBC, $P<0.05)$ (Fig. 2).

Measurement of urea production in control and FP-pretreated $R B C$. Urea production was used as an index for changes in arginase activity following incubation with L-Arg and was measured in total RBC lysates, cytosol, or RBC membranes prepared from control or FP-treated RBC. Figure $3 A$ shows that urea produced by total lysates from FP-RBC after incubation with increasing concentrations of L-Arg was significantly higher compared with controls. Interestingly, an enhanced production of urea in FP-RBC was observed when the assay was performed in the cytosol fraction, whereas no differences were shown when L-Arg was incubated with RBC membranes, representing only membrane-bound arginase (Fig. 3B).

Urea production in intact $\mathrm{RBC}$ pretreated with $\mathrm{FP}$ and measured in the extracellular medium after 16-h incubation was increased by FP in a dose-dependent way (Fig. 4A). The
Fig. 1. A and $C$ : Ultraviolet-visible (UV/Vis) spectra of $10 \mathrm{mM}$ ferriprotoporphyrin IX (FP) alone (solid line) and in the presence of $250 \mathrm{mM}$ L-arginine (L-Arg) (dashed line; $A$ ) or $250 \mathrm{mM}$ L-lysine (L-Lys) (dashed line; $C$ ). B: UV/Vis spectra of $10 \mathrm{mM}$ hematoporphyrin IX (HP) alone (solid line) and in the presence of $250 \mathrm{mM}$ L-Arg (dashed line). Abs, absorbance.

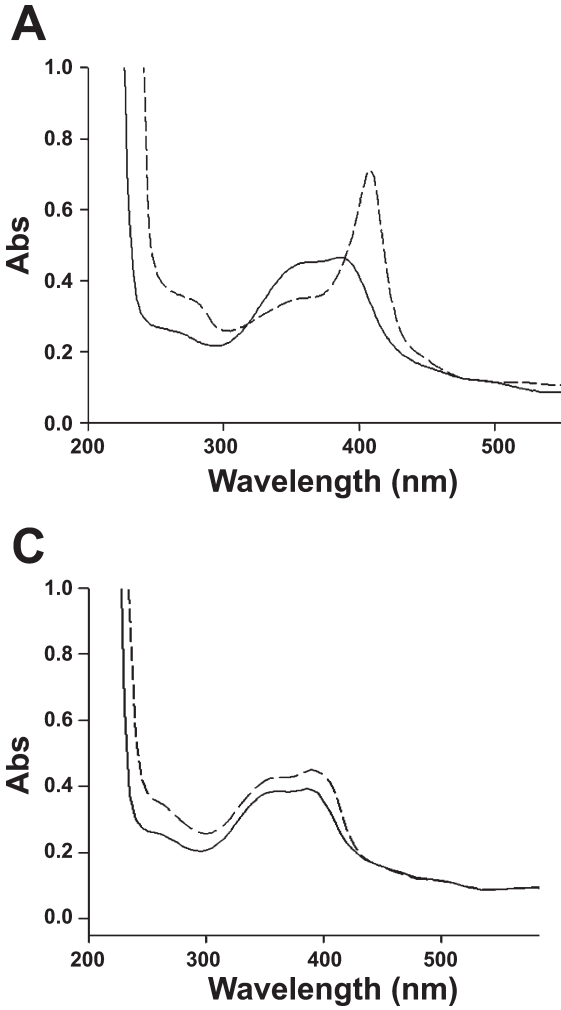

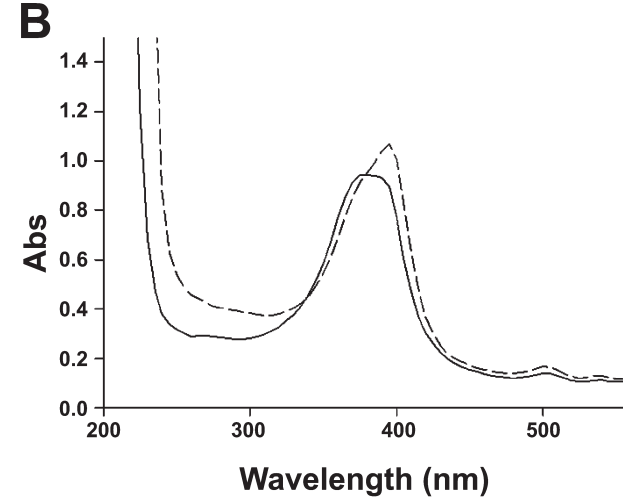




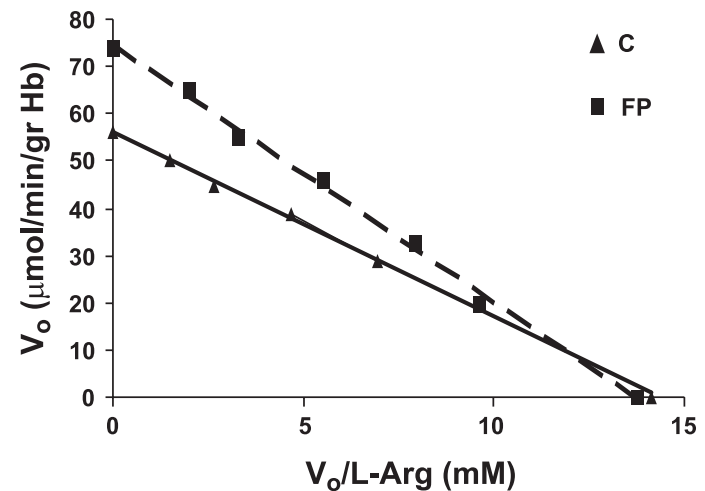

Fig. 2. Eadie-Hofstee graph for arginase activity of control (C) and $40 \mu \mathrm{M}$ FP-pretreated (FP) red blood cells (RBC). Each data point represents a triplicate sample of 4 separate experiments. $V_{0}$, initial velocity.

higher urea concentrations (expressed as $\mathrm{mM}$ values) measured in the extracellular medium could partly be explained by the presence of FP-induced hemolysis $(2-2.5 \%$ in FP RBC vs. $0.8-1 \%$ in controls), which causes the release of intracellular arginase. However, differences between control and FP-treated $\mathrm{RBC}$ remained significant when the urea levels were expressed
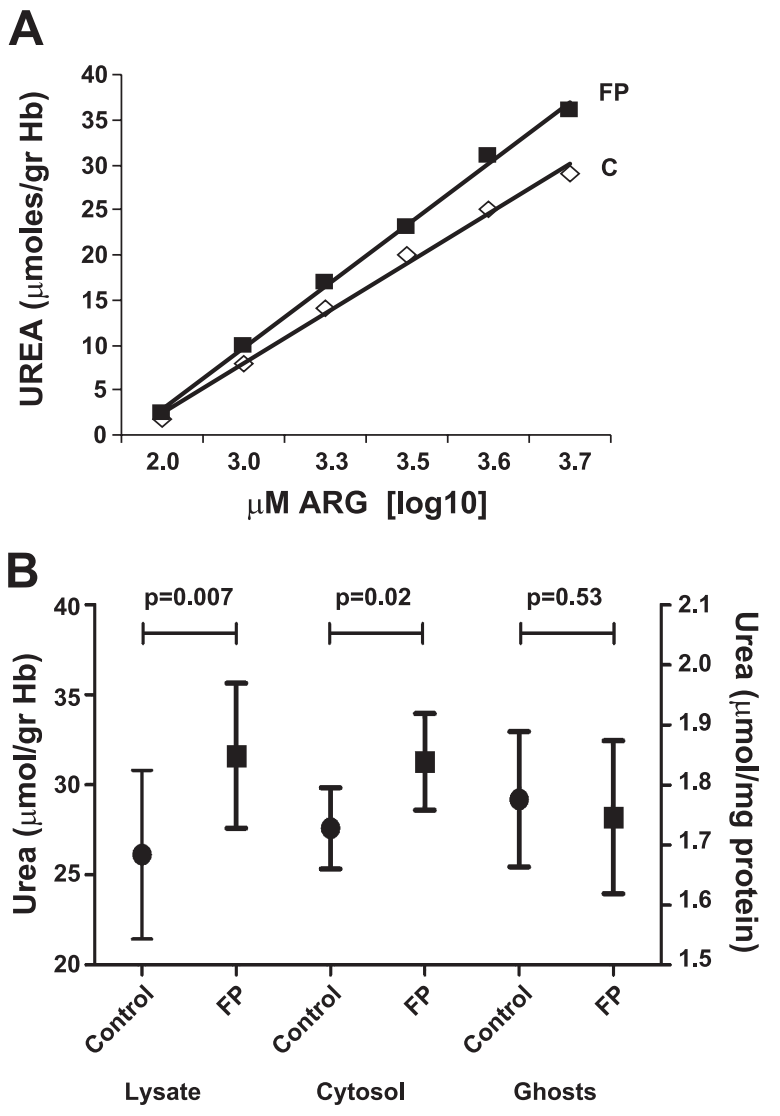

Fig. 3. A: urea production in total lysates of control $\mathrm{RBC}$ or $\mathrm{RBC}$ pretreated with $40 \mu \mathrm{M} \mathrm{FP}\left(60 \mathrm{~min}, 37^{\circ} \mathrm{C}\right)$. Incubation was performed for $16 \mathrm{~h}$ at $37^{\circ} \mathrm{C}$ in the presence of increasing concentrations of L-Arg $(0.1-5 \mathrm{mM})$. This is a representative experiment out of 5 , made in triplicate. $B$ : mean urea values from 5 paired lysates, cytosols, and ghosts prepared from control and FP samples $\left(40 \mu \mathrm{M} \mathrm{FP}, 60 \mathrm{~min}, 37^{\circ} \mathrm{C}\right.$ ). Incubation was performed for $16 \mathrm{~h}$ at $37^{\circ} \mathrm{C}$ in the presence of $5 \mathrm{mM} \mathrm{L}$-Arg. Paired comparisons were made by Student's $t$-test.
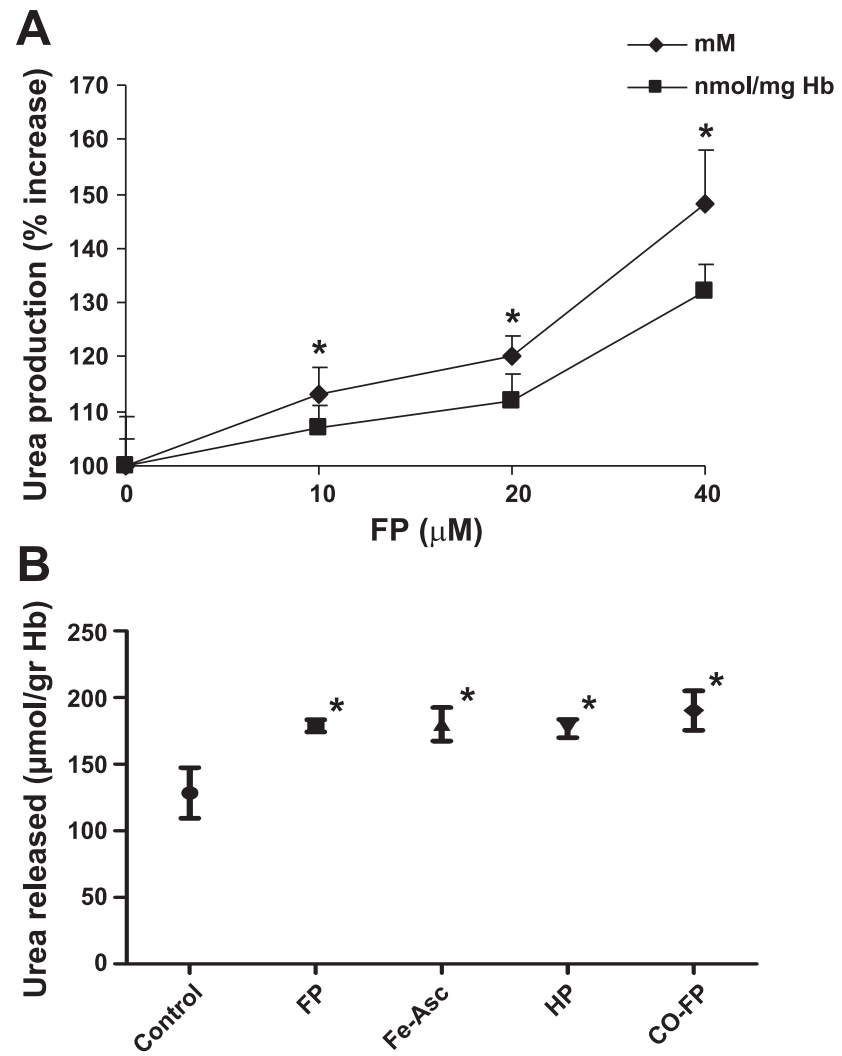

Fig. 4. A: urea released in the extracellular medium by control RBC or RBC pretreated for $60 \mathrm{~min}$ with increasing concentrations of FP and then incubated for $16 \mathrm{~h}$ at $37^{\circ} \mathrm{C}$ in the presence of $5 \mathrm{mM} \mathrm{L}$-Arg. Results are expressed as absolute values $(\mathrm{mM})$ or per milligram of $\mathrm{Hb}$. Results are means \pm SD of 4 experiments. ${ }^{*} P<0.01$ vs. control. $B$ : urea released in the extracellular medium ( $n=5$ experiments) by control RBC, RBC pretreated for 60 min with $40 \mu \mathrm{M}$ FP or HP, or RBC pretreated for $3 \mathrm{hrs}$ with $\mathrm{Fe}=$ ascorbate $(\mathrm{Fe}-\mathrm{Asc}$, 0.3-0.5 mM). CO-FP indicates that the RBC suspension was exposed for 10 min to a carbon monoxide atmosphere before treatment with $40 \mu \mathrm{M} \mathrm{FP}$. Bars represent means and 95\% confidence intervals (CI). Comparison over all groups: $P<0.001$ (4 df); paired comparisons with control: $* P=0.04$ by Wilcoxon signed-rank test.

as nanomoles per milligram of $\mathrm{Hb}$, which corrects for the degree of hemolysis [mean (SD): 148\% (10) absolute increase at $40 \mu \mathrm{M}$ FP before correction vs. $132 \%$ (5) increase after correction]. In contrast with the change in arginase activity, the activity of lactate dehydrogenase referred to the $\mathrm{Hb}$ content of the supernatants was identical in control and FP-treated RBC (not shown). The effects of oxidative stress on urea production are shown in Fig. 4B. Pretreatment of RBC with the prooxidant system $\mathrm{Fe}$-ascorbate caused a significant increase of urea released in the extracellular medium. To evaluate whether the FP-related increase in urea depends on its oxidative properties, we studied urea production in RBC incubated with HP, which is depleted of the iron II/iron III redox cycling of porphyrin. Urea production remained similarly increased in this system, suggesting that FP-induced oxidative stress is not required for FP-induced activation of the enzyme. Also, in CO-treated RBC urea production was significantly higher in $\mathrm{RBC}$ incubated with FP. In these RBC, CO binding to heme-iron completely prevented the dose- and time-dependent formation of MetHb induced by FP (not shown).

Arginine influx. In addition to free, nonsaturable diffusion, L-Arg influx into RBC is supported by the carrier systems $\mathrm{y}+$ 
(or CAT) and $\mathrm{y}+\mathrm{L}(3,20)$. Kinetics of $\mathrm{L}$-Arg influx were determined under conditions allowing us to assess the individual contributions of systems $y+$ and $y+L$, by selective inhibition of the systems by NEM and leucine, respectively (3). Figure 5 shows that FP impairs the total L-Arg influx in a dose-dependent manner (Fig. 5A). The rate of L-Arg uptake by $\mathrm{RBC}$ treated with $40 \mu \mathrm{M}$ FP is reduced by $\sim 40 \%$ independent of the incubation time (Fig. 5B). From the values reported in Fig. $6 A$ corrected for the diffusion component, it was calculated that contribution of systems $\mathrm{y}+$ and $\mathrm{y}+\mathrm{L}$ to the total transport was about $68 \%$ and $17 \%$, respectively, in control $\mathrm{RBC}$ and $72 \%$ and $7 \%$ in FP-RBC. Impairment of $\mathrm{y}+\mathrm{L}$ transport by FP was compensated by a higher percentage of L-Arg free diffusion (22\% in FP RBC vs. $15 \%$ in control RBC). By comparing the absolute amount of $\mathrm{L}-\mathrm{Arg}$ influx (cpm $\left[{ }^{3} \mathrm{H}\right]$ arginine $\left./ 10^{7} \mathrm{RBC}\right)$, it can be calculated that in FP-RBC $\mathrm{y}+$ and $\mathrm{y}+\mathrm{L}$ transports were reduced by $30 \%$ and $73 \%$, respectively, with no changes in the free diffusion. Preliminary experiments in our laboratory showed that pretreatment with FP also causes a dose-dependent impairment of the total L-Arg influx into endothelial cells (HMEC), with a maximum of $30 \%$ inhibition at a FP concentration of $40 \mu \mathrm{M}$ (data not shown).

\section{DISCUSSION}

Erythrocytes represent an important compartment for arginine metabolism, because arginine can be hydrolyzed to ornithine and urea by arginase (isoform I) or converted to $\mathrm{NO}^{\circ}$ and citrulline by a functional endothelial NOS (eNOS) activity
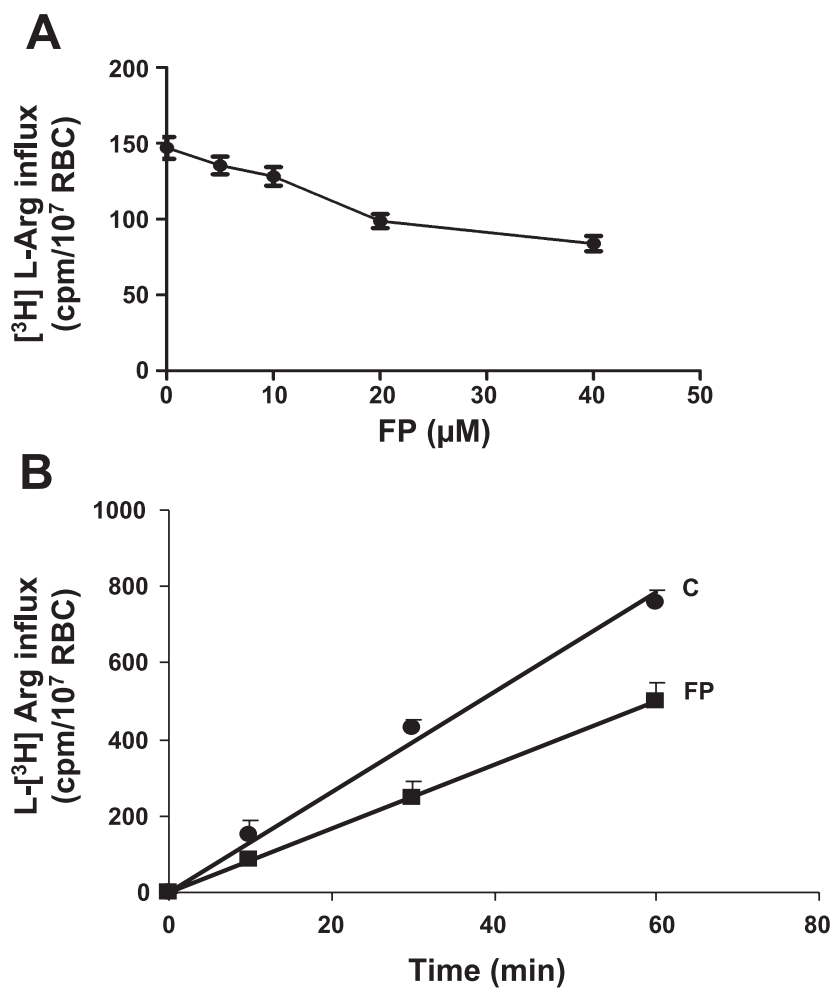

Fig. 5. A: total influx of $\mathrm{L}-\left[{ }^{3} \mathrm{H}\right] \operatorname{Arg}(200 \mu \mathrm{M})$ in control RBC or RBC pretreated with increasing concentrations of FP. Influx of L-Arg was determined over 5 -min incubation. Bars represent mean (5 experiments) and 95\% CI. Test for trend: $P<0.001$. B: time course of total $\mathrm{L}-\left[{ }^{3} \mathrm{H}\right] \operatorname{Arg}(200 \mu \mathrm{M})$ influx in control RBC or RBC pretreated with $40 \mu \mathrm{M}$ FP. Results are means \pm SD of 4 experiments.

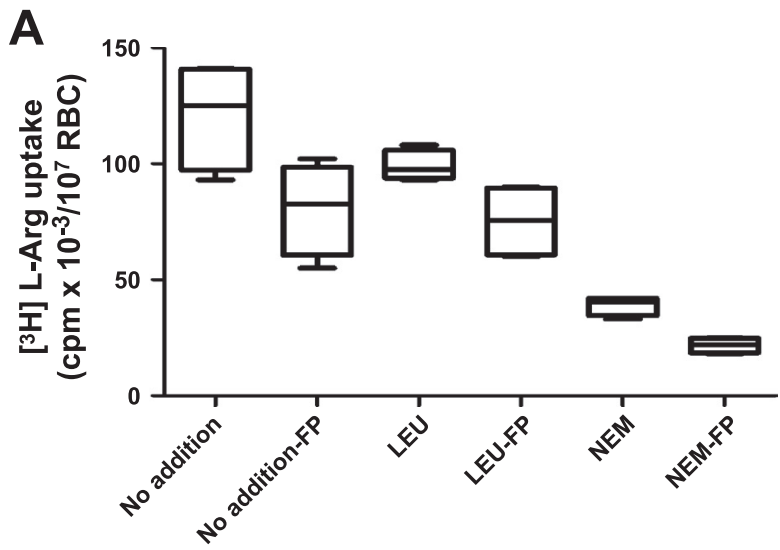

B

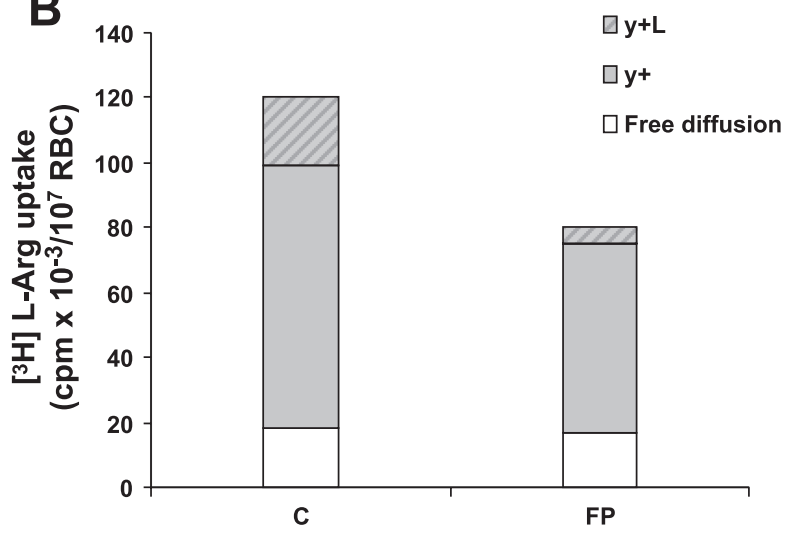

Fig. 6. A: $\mathrm{L}-\left[{ }^{3} \mathrm{H}\right] \mathrm{Arg}$ uptake into control RBC or RBC pretreated with $40 \mu \mathrm{M}$ FP $(n=4$ experiments/treatment). Rates were measured in the absence (no addition) or the presence of either $1 \mathrm{mM}$ unlabeled leucine (Leu) or $2 \mathrm{mM}$ $\mathrm{N}$-ethylmaleimide (NEM). Boxes indicate medians and interquartile ranges. Bars represent upper and lower adjacent values. $P=0.068$ for each paired comparison between treatment and control by Wilcoxon signed-rank test. $B$ : contribution of transport systems $\mathrm{y}+\mathrm{L}$ and $\mathrm{y}+$ and free diffusion to the total $\mathrm{L}-\left[{ }^{3} \mathrm{H}\right] \mathrm{Arg}$ transport in control RBC or RBC pretreated with $40 \mu \mathrm{M}$ FP.

(15). Among its many other functions, $\mathrm{NO}^{\circ}$ is pivotal for proper endothelial function, and hypoargininemia and reduced NO availability have been implemented in the pathophysiology of severe malaria (42). Under conditions of low L-Arg concentrations NOS is uncoupled, producing reactive oxygen species instead of NO (41). Also, since L-Arg is essential for both proliferation and differentiation of erythroid cells (36), inhibition of L-Arg influx by FP may have critical consequences for the hematopoiesis processes already impaired by proinflammatory cytokines and hemozoin (5). Impaired $\mathrm{NO}^{\circ}$ production could enhance the rigidifying effects on RBC mediated by FP-induced band 3 phosphorylation $(2,25,29)$. Elevated arginase activity has been reported in both plasma and RBC lysate in SCD, a hemoglobinopathy sharing some important pathophysiological features with $P$. falciparum malaria $(11,21)$. However, while the elevated activity in plasma can be easily accounted for by RBC lysis during intravascular hemolysis, the possibility that arginase in the intra- or extracellular compartment may be directly activated by heme has not been investigated. Arginase activity is enhanced in vitro by hydroxyl radicals produced by the Fenton reaction (12) and is diminished in human RBC after consumption of flavanol-rich bev- 
erages (34). Indeed, in agreement with the above findings, we could show an increase in arginase activity in RBC pretreated with the prooxidant system $\mathrm{FeSO}_{4}$-ascorbate. Although the precise mechanisms of these effects have not been clarified, our hypothesis is that FP might enhance arginase activity of $\mathrm{RBC}$ through oxidative modifications, resulting in reduced $\mathrm{NO}$ synthesis and/or availability. However, it appeared that FP is able to enhance arginase activity in an oxidative-independent way. RBC pretreated with HP (the porphyrin analog devoid of the oxidative iron) showed an increase in urea production similar to that of FP-treated RBC, indicating that oxidative stress cannot explain the increase of enzymatic activity induced by FP and suggesting a direct effect of the porphyrin on the enzyme. This is also supported by the finding that enhanced arginase activity induced by FP can neither be prevented nor reduced by the radical scavengers $\mathrm{NAC}$ and $\mathrm{SZ}$ or by $\mathrm{Hb}$ saturated with $\mathrm{CO}$. $\mathrm{CO}$ binds to iron heme, preventing it from participating in redox cycling as illustrated by the prevention of FP-induced formation of MetHb. This potentially antioxidant mechanism of CO limiting superoxide-dependent Fenton reactions has recently been proposed as a mechanism for the protective effect of $\mathrm{CO}$ in murine cerebral malaria (28).

The reported arginase activities and $K_{\mathrm{m}}$ in control RBC were in agreement with other authors $(11,39)$ and were both increased by FP. The capability of L-Arg to interact with FP (shown by the shift of the UV/Vis spectra) and inducing the formation of FP monomers and/or adducts of L-Arg-FP suggests a different interaction between arginase and L-Arg being responsible for these modifications. A similar interaction can be hypothesized between HP and L-Arg, even though the L-Arg-induced shift of the UV/Vis spectrum of HP is less prominent since here HP is already mainly present as a monomer. The increase in arginase activity was similar in the total $\mathrm{RBC}$ suspension compared with the extracellular medium and confirmed by the accumulation of urea, which can move freely across the RBC membrane.

In addition to increased arginase activity, intracellular NO production could also be compromised by reduced transmembrane transport of L-Arg into the RBC. We could show that FP inhibits $\mathrm{y}+$ and $\mathrm{y}+\mathrm{L}$ transmembrane transports of $\mathrm{L}-\mathrm{Arg}$ by $30 \%$ and $73 \%$, respectively, with no changes in the free diffusion of L-Arg.

In agreement with published data, the relative contribution of transport system $\mathrm{y}+$ to the $\mathrm{L}$-Arg transport in control RBC was $\sim 68 \%$ (3). Impairment of system y+ observed in FP-RBC was not unexpected because of its known sensitivity to the sulfydryl reagent NEM and the reactivity of FP with sulfydryl groups (26). The mechanisms underlying the inhibition of system $\mathrm{y}+\mathrm{L}$ by FP need further investigation.

FP-induced hemolysis was a potential confounder in our experiments. Arginase and $\mathrm{Hb}$ are both released from RBC as they undergo lysis. However, after correction for the $\mathrm{Hb}$ content of the sample, the arginase activity in the extracellular medium remained significantly increased. This implies that the increase in enzyme activity was exclusively resulting from the effects of porphyrin on the protein.

It has been demonstrated that the activity of RBC arginase is enhanced after binding to the membrane through membrane protein flotillin-1 (13). Interestingly, we did not find any difference in the production of urea when L-Arg was incubated with RBC membranes prepared from control and FP-treated
RBC. This observation excludes the possibility that translocation to the membrane might be the responsible molecular mechanism for FP-induced activation of RBC arginase. The enhanced production of urea induced by FP was observed only in the total and the cytosolic fraction of RBC and can therefore only be attributed to the soluble fraction of enzyme.

Our findings show that free heme can significantly impair L-Arg uptake through CAT and enhances L-Arg consumption through RBC arginase depleting the L-Arg pool as a source for NO production. The rate of L-Arg uptake and degradation by arginase may limit the rate of NO synthesis by FP-treated RBC. Release of a more active arginase by FP-destabilized RBC during intravascular hemolysis could also contribute to and worsen hypoargininemia, reducing L-Arg availability for NO synthesis in endothelial cells. In addition, the released heme could further impair transport of L-Arg into endothelial cells, because we showed that FP has this effect on L-Arg transport into HMEC in vitro. This finding was not unexpected since the same cation amino acid system $\mathrm{y}^{+}$is responsible for most of the transmembranous L-Arg transport in these cells $(39,40)$. Further investigations are needed to quantify the effects of FP on endothelial $\mathrm{y}+$ and $\mathrm{y}+\mathrm{L}$ Arg transporters. Although intracellular L-Arg concentrations greatly exceed the very low $K_{\mathrm{m}}$ of NOS (micromolar range), dependence of eNOS activity from the arginine availability has been observed in endothelial cells and called the "arginine paradox" (17). The arginine paradox has been explained by the physical association of L-Arg transporters and eNOS in caveolar complexes providing a mechanism for direct channeling of extracellular L-Arg for NO synthesis (19).

In conclusion, we have shown that free heme impairs L-Arg transport across the RBC membrane and increases intra- and extraerythrocytic arginine breakdown. These mechanisms can contribute to the observed reduced NO production in severe malaria, which has several important pathophysiological implications.

\section{ACKNOWLEDGMENTS}

The authors thank Prof. Donatella Taramelli and Dr. Nicoletta Basilico for providing HMEC cells, Prof. Nicholas M. Anstey of the International Health Division, Menzies School of Health Research and Charles Darwin University (Darwin, Australia) and Dr. Diego Monti of the Department of Organic Chemistry, University of Milan (CNR-ISTM) for helpful discussions, and Dr. Sue Lee for statistical analysis of data.

\section{GRANTS}

This publication was generated in the context of the AntiMal project, funded under the 6th Framework Programme of the European Community (Contract No. IP-018834 to Prof. Donatella Taramelli). The authors are solely responsible for its content, it does not represent the opinion of the European Community, and the Community is not responsible for any use that might be made of the information contained therein. We also acknowledge the Associazione Volontari Italiani Sangue (AVIS Comunale Milano) for providing fresh blood and approval of the research project and the financial support of the University of Milan (First 2006-2008).

\section{DISCLOSURES}

No conflicts of interest, financial or otherwise, are declared by the author(s).

\section{REFERENCES}

1. Anstey NM, Weinberg JB, Hassanali MY, Mwaikambo ED, Manyenga D, Misukonis MA, Arnelle DR, Hollis D, McDonald MI, Granger DL. Nitric oxide in Tanzanian children with malaria: inverse relationship 
between malaria severity and nitric oxide production/nitric oxide synthase type 2 expression. $J$ Exp Med 184: 557-567, 1996.

2. Bottini E. Association between cytosolic low molecular weight phosphotyrosine-phosphatase and malaria-a possible mechanism. Am J Phys Anthropol 108: 241-244, 1999.

3. Boyd CA, Deves R, Laynes R, Kudo Y, Sebastio G. Cationic amino acid transport through system $\mathrm{y}+\mathrm{L}$ in erythrocytes of patients with lysinuric protein intolerance. Pflügers Arch 439: 513-516, 2000.

4. Brown SB, Shillcock M, Jones P. Equilibrium and kinetic studies of the aggregation of porphyrins in aqueous solution. Biochem $J$ 153: 279-285, 1976.

5. Casals-Pascual C, Kai O, Cheung JO, Williams S, Lowe B, Nyanoti M, Williams TN, Maitland K, Molyneux M, Newton CR, Peshu N, Watt SM, Roberts DJ. Suppression of erythropoiesis in malarial anemia is associated with hemozoin in vitro and in vivo. Blood 108: 2569-2577, 2006.

6. Chou AC, Fitch CD. Mechanism of hemolysis induced by ferriprotoporphyrin IX. J Clin Invest 68: 672-677, 1981 .

7. Coghi P, Basilico N, Taramelli D, Chan WC, Haynes RK, Monti D. Interaction of artemisinins with oxyhemoglobin Hb-FeII, Hb-FeII, carboxyHb-FeII, heme-FeII, and carboxyheme FeII: significance for mode of action and implications for therapy of cerebral malaria. Chem Med Chem 4: 2045-2053, 2009.

8. Corraliza IM, Campo ML, Soler G, Modolell M. Determination of arginase activity in macrophages: a micromethod. J Immunol Methods 174: 231-235, 1994

9. Dondorp AM, Pongponratn E, White NJ. Reduced microcirculatory flow in severe falciparum malaria: pathophysiology and electron-microscopic pathology. Acta Trop 89: 309-317, 2004.

10. Iuvone T, D'Acquisto F, Carnuccio R, Di Rosa M. Nitric oxide inhibits LPS-induced tumor necrosis factor synthesis in vitro and in vivo. Life Sci 59: PL207-PL211, 1996.

11. Iyamu EW, Cecil R, Parkin L, Woods G, Ohene-Frempong $\mathbf{K}$, Asakura T. Modulation of erythrocyte arginase activity in sickle cel disease patients during hydroxyurea therapy. Br J Haematol 131: 389 394, 2005.

12. Iyamu EW, Perdew H, Woods GM. Cysteine-iron promotes arginase activity by driving the Fenton reaction. Biochem Biophys Res Commun 376: 116-120, 2008.

13. Jiang M, Ding Y, Su Y, Hu X, Li J, Zhang Z. Arginase-flotillin interaction brings arginase to red blood cell membrane. FEBS Lett 580 : 6561-6564, 2006.

14. Kleinbongard P, Keymel S, Kelm M. New functional aspects of the L-arginine-nitric oxide metabolism within the circulating blood. Thromb Haemost 98: 970-974, 2007.

15. Kleinbongard P, Schulz R, Rassaf T, Lauer T, Dejam A, Jax T, Kumara I, Gharini P, Kabanova S, Ozuyaman B, Schnurch HG, Godecke A, Weber AA, Robenek M, Robenek H, Bloch W, Rosen P, Kelm M. Red blood cells express a functional endothelial nitric oxide synthase. Blood 107: 2943-2951, 2006.

16. Korman SH, Gutman A, Stemmer E, Kay BS, Ben-Neriah Z, Zeigler M. Prenatal diagnosis for arginase deficiency by second-trimester fetal erythrocyte arginase assay and first-trimester ARG1 mutation analysis. Prenat Diagn 24: 857-860, 2004.

17. Kurz S, Harrison DG. Insulin and the arginine paradox. J Clin Invest 99 : 369-370, 1997.

18. Lopansri BK, Anstey NM, Weinberg JB, Stoddard GJ, Hobbs MR, Levesque MC, Mwaikambo ED, Granger DL. Low plasma arginine concentrations in children with cerebral malaria and decreased nitric oxide production. Lancet 361: 676-678, 2003.

19. McDonald KK, Zharikov S, Block ER, Kilberg MS. A caveolar complex between the cationic amino acid transporter 1 and endothelial nitricoxide synthase may explain the "arginine paradox." J Biol Chem 272: 31213-31216, 1997

20. Mendes Ribeiro AC, Hanssen H, Kiessling K, Roberts NB, Mann GE, Ellory JC. Transport of L-arginine and the nitric oxide inhibitor $N^{\mathrm{G}}$ monomethyl-L-arginine in human erythrocytes in chronic renal failure. Clin Sci (Lond) 93: 57-64, 1997.

21. Morris CR, Kato GJ, Poljakovic M, Wang X, Blackwelder WC, Sachdev V, Hazen SL, Vichinsky EP, Morris SM Jr, Gladwin MT. Dysregulated arginine metabolism, hemolysis-associated pulmonary hypertension, and mortality in sickle cell disease. JAMA 294: 81-90, 2005
22. Mukai M, Savard PY, Ouellet H, Guertin M, Yeh SR. Unique ligandprotein interactions in a new truncated hemoglobin from Mycobacterium tuberculosis. Biochemistry 41: 3897-3905, 2002.

23. Munder M, Eichmann K, Moran JM, Centeno F, Soler G, Modolell M. Th1/Th2-regulated expression of arginase isoforms in murine macrophages and dendritic cells. J Immunol 163: 3771-3777, 1999.

24. Nuchsongsin F, Chotivanich K, Charunwatthana P, Omodeo-Sale F, Taramelli D, Day NP, White NJ, Dondorp AM. Effects of malaria heme products on red blood cell deformability. Am J Trop Med Hyg 77: 617-622, 2007.

25. Omodeo-Sale F, Cortelezzi L, Riva E, Vanzulli E, Taramelli D. Modulation of glyceraldehyde 3 phosphate dehydrogenase activity and tyr-phosphorylation of Band 3 in human erythrocytes treated with ferriprotoporphyrin IX. Biochem Pharmacol 74: 1383-1389, 2007.

26. Omodeo Salé F, Motti A, Dondorp A, White NJ, Taramelli D. Destabilization and subsequent lysis of human erythrocytes induced by Plasmodium falciparum heme products. Eur J Haematol 74: 324-332, 2005.

27. Ozuyaman B, Grau M, Kelm M, Merx MW, Kleinbongard P. RBC NOS: regulatory mechanisms and therapeutic aspects. Trends Mol Med 14: 314-322, 2008

28. Pamplona A, Ferreira A, Balla J, Jeney V, Balla G, Epiphanio S, Chora A, Rodrigues CD, Gregoire IP, Cunha-Rodrigues M, Portugal S, Soares MP, Mota MM. Heme oxygenase-1 and carbon monoxide suppress the pathogenesis of experimental cerebral malaria. Nat Med 13: 703-710, 2007.

29. Pantaleo A, Ferru E, Giribaldi G, Mannu F, Carta F, Matte A, de Franceschi L, Turrini F. Oxidized and poorly glycosylated band 3 is selectively phosphorylated by Syk kinase to form large membrane clusters in normal and G6PD-deficient red blood cells. Biochem J 418: 359-367, 2009.

30. Pawloski JR, Swaminathan RV, Stamler JS. Cell-free and erythrocytic $S$-nitrosohemoglobin inhibits human platelet aggregation. Circulation 97: 263-267, 1998.

31. Radomski MW, Palmer RM, Moncada S. The anti-aggregating properties of vascular endothelium: interactions between prostacyclin and nitric oxide. Br J Pharmacol 92: 639-646, 1987.

32. Radomski MW, Palmer RM, Moncada S. Endogenous nitric oxide inhibits human platelet adhesion to vascular endothelium. Lancet 2: 1057-1058, 1987.

33. Rother RP, Bell L, Hillmen P, Gladwin MT. The clinical sequelae of intravascular hemolysis and extracellular plasma hemoglobin: a novel mechanism of human disease. JAMA 293: 1653-1662, 2005.

34. Schnorr O, Brossette T, Momma TY, Kleinbongard P, Keen CL, Schroeter H, Sies H. Cocoa flavanols lower vascular arginase activity in human endothelial cells in vitro and in erythrocytes in vivo. Arch Biochem Biophys 476: 211-215, 2008.

35. Serirom S, Raharjo WH, Chotivanich K, Loareesuwan S, Kubes P, Ho M. Anti-adhesive effect of nitric oxide on Plasmodium falciparum cytoadherence under flow. Am J Pathol 162: 1651-1660, 2003.

36. Shima Y, Maeda T, Aizawa S, Tsuboi I, Kobayashi D, Kato R, Tamai I. L-Arginine import via cationic amino acid transporter CAT1 is essential for both differentiation and proliferation of erythrocytes. Blood 107: 1352-1356, 2006.

37. Wagener FA, Eggert A, Boerman OC, Oyen WJ, Verhofstad A, Abraham NG, Adema G, van Kooyk Y, de Witte T, Figdor CG. Heme is a potent inducer of inflammation in mice and is counteracted by heme oxygenase. Blood 98: 1802-1811, 2001.

38. Winterbourn CC. Oxidative reactions of hemoglobin. Methods Enzymol 186: 265-272, 1990

39. Wu G, Morris SM Jr. Arginine metabolism: nitric oxide and beyond. Biochem J 336: 1-17, 1998

40. Wyatt AW, Steinert JR, Mann GE. Modulation of the L-arginine/nitric oxide signalling pathway in vascular endothelial cells. Biochem Soc Symp 71: 143-156, 2004.

41. Xia Y, Dawson VL, Dawson TM, Snyder SH, Zweier JL. Nitric oxide synthase generates superoxide and nitric oxide in arginine-depleted cells leading to peroxynitrite-mediated cellular injury. Proc Natl Acad Sci USA 93: 6770-6774, 1996

42. Yeo TW, Lampah DA, Gitawati R, Tjitra E, Kenangalem E, McNeil YR, Darcy CJ, Granger DL, Weinberg JB, Lopansri BK, Price RN, Duffull SB, Celermajer DS, Anstey NM. Impaired nitric oxide bioavailability and L-arginine reversible endothelial dysfunction in adults with falciparum malaria. J Exp Med 204: 2693-2704, 2007. 